\title{
AEROMAGNETIC MAP OF PARTS OF THE ELIZABETHTOWN AND PORT HENRY QUADRANGLES ESSEX COUNTY, NEW YORK \\ By
}

James R. Balsley and Randolph W. Bromery

GEOPHYSICAL INVESTIGATIONS

MAP GP-506

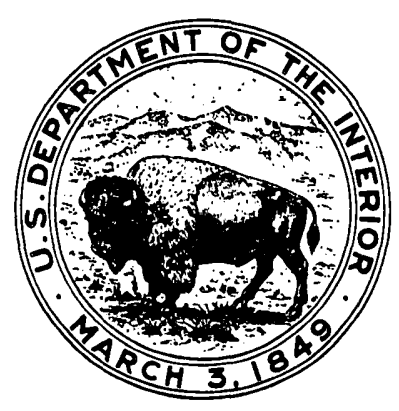

